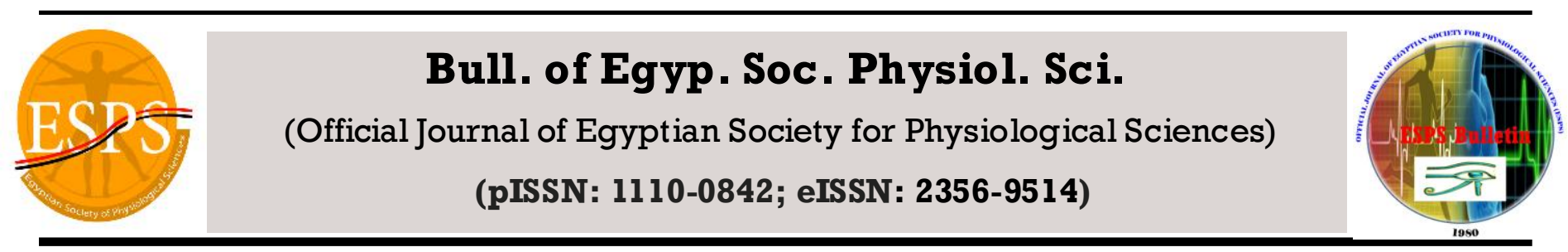

\title{
Effects of vitamin D3 on PPAR- $\alpha$ and its target gene NFKBIA on a Rat Model of High Carbohydrate High Fat diet induced Non Alcoholic Steatohepatitis
}

\author{
${ }^{1}$ Mohamed Eldosoky, ${ }^{2}$ Sally Abed, ${ }^{3}$ Mohamed Elshafey \\ ${ }^{1}$ Department of Medical Physiology, Faculty of Medicine, Mansoura University, Egypt \\ ${ }^{2}$ Department of Tropical Medicine, Faculty of Medic ine, Mansoura University, Egypt \\ ${ }^{3}$ Department of Human Anatomy and Embryology, Faculty of Medicine, Mansoura University, Egypt
}

Recei ved: 10 Oct, 2015

Accepted: 24 Dec 2015

Available online: 1 Jan 2016

\section{Keywords}

- Vitamin D3

- HCHFD

- Nonalcoholic

Steatohepatitis

- PPAR- $\alpha$

- NFKBIA.

\begin{abstract}
Objectives: Accumulating data suggesting that Vitamin D3 could be of a potential therapeutic value for non-alcoholic fatty liver disease (NAFLD), but its underlying mechanisms are still under research .Vitamin D3 up regulates PPAR- $\alpha$ and downstream gene nuclear factor-kappa-B inhibitor subunit-alpha (NFKBIA) which may represent a novel strategy for the management of NASH. Therefore, in this study, we investigated the possible protective role of vitamin D3 on high carbohydrate high fat diet (HCHFD) animal model of NASH through PPAR- $\alpha$ and NFKBIA pathway Methods: Thirty male Sprague-Dawley rats were equally divided into three groups; Group I: (negative control group) fed standard rat chow diet for 8 weeks. Group II: received HCHFD for 8 weeks. Group III: fed as group II for 8 weeks and received also, I.P administration of vitamin D3 at a dose of $5 \mu \mathrm{g} / \mathrm{kg}$ twice weekly from the fourth week till the end of the study. At the end of the experiment, serum trig lycerides, total cholesterol, liver enzy mes, serum albu min, serum bilirubin and liver tissue oxidative stress markers (MDA, SOD and GSH) were measured. Hepatic histopathological alterations were assessed by hematoxy lin and eosin, Masson's trichrome, and Oil Red O staining ; the expressions of NF- $\kappa$ B p65 (ReIA) was estimated in liver tissues using immunohistochemistry and the expression of hepatic PPAR- $\alpha$ and NFKBIA genes were estimated at the level of mRNA by quantitative real-time PCR. Results: Nonalcoholic steatohepatitis (NASH) model was confirmed by histopathological examination as indicated by elevated NAFLD activity score (NAS) as well as elevation of serum liver enzy mes , hyperlipidemia in the form elevated plasma triglycerides and total cholesterol, oxidative stress state (high MDA, low GSH and SOD) and down regulation of PPAR- $\alpha$ and NFKBIA mRNA in liver tissues which was concomitant with up regulation of inflammatory marker NF- $\kappa$ Bp65(ReIA). On the other hand, vitamin D3 a meliorated NASH by attenuation of oxidative stress (low MDA, high GSH and SOD) and up regulation of PPAR- $\alpha$ and NFKBIA genes at the level of mRNA in the liver tissues which was accompanied by decrease in hepatocyte nuclear NF- $\kappa$ B-p65 (ReIA) immunohistochemical brownish staining. Conclusion: Vitamin D3 attenuates NASH in HCHFD rat model by attenuation of redox state and up regulation of PPAR- $\alpha$ and its downstream gene NFKBIA in liver tissues
\end{abstract}

Corres ponding author: Dr. Mohamed Eldosoky, Lecturer of Medical Physiology, Faculty of Medic ine, Mansoura University, Egypt. Tel: +201001083633. Email:dr_m_dosoky2006@yahoo.com 


\section{INTRODUCTION}

Nonalcoholic fatty liver disease (NAFLD) is now considered the most common chronic liver disease all over the world, affecting $20-35 \%$ of the adults in the general population [1]. NAFLD comprises a disease spectrum ranging from simple steatosis (SS), through non-alcoholic steatohepatitis (NASH) to hepatic fibrosis, then cirrhosis and ultimately hepatocellular carcinoma (HCC) [2]. The progression from SS to NASH is an essential step in NAFLD progression and people with NASH accounts for $15-30 \%$ of NAFLD patients and is anticipated to be the main cause of liver transplantation by 2020 [3].

Much research has been directed on NAFLD pathogenesis over the previous decades, till now it is not completely understood, and no fully welldefined treatment has been established. The pathogenesis of NAFLD is as yet in view of theories, a well-accepted two hit theory by Day and Jones, [4] was proposed; the primary hit is liver cells triglyceride accumulation, followed by initiators of the second hit which may be either proinflammatory mediators, mitochondrial abnormality [5,6]; elevated oxidative stress condition [7]with subsequent apoptosis [8,9].

The nuclear receptors peroxisome proliferatoractivated receptor alpha (PPAR- $\alpha$ ) is highly expressed in liver cells and exerts a pleiotropic effect such as modulation of fatty acid transport, $\beta$-oxidation and regulation of inflammatory reaction [10]. Stienstra et al., [11] and Abdelmegeed et al., [12] suggested that PPAR- $\alpha$ has a beneficial role against both liver steatosis and inflammatory reaction in NASH as evidenced by the increased susceptibility to NASH of PPAR$\alpha$ knockout mice; thus PPAR- $\alpha$ activation could be an important therapeutic target in NASH.

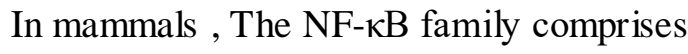
of five proteins, p65 or RelA, RelB, c-Rel, p50 or

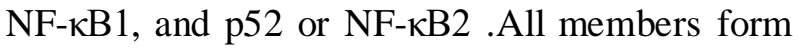
homo or heterodimers and have in common the same 300 terminal amino acid which is called Rel homology domain (RHD) [13,14], of the NF- $\kappa B$ five proteins ; p65 protein is the most dominant and is present in heterodimer with p50 [15]. One of the most important controller of mammalian $\mathrm{NF \kappa B}$ is inhibitors of NFkB ( $\mathrm{IkB} \alpha)$; known also as Nuclear factor-kappa-B inhibitor subunit-alpha (NFKBIA) ; in non-stimulated cell ; NFKBIA combines with the p50/p65 heterodimer, sequestrating it in the cytoplasm thus hindering nuclear translocation of $\mathrm{NF \kappa B}$ and activation of target gene transcription [16] . Iкb $\alpha$ or NFKBIA is a target gene PPAR- $\alpha$ [17-18].

The transcription factor NF- $\mathrm{kB}$ is considered the genetic switch that regulates the genes responsible for inflammatory, immune and stress response [19]. Siebenlist et al., [20] stated that it plays a pivotal role in the decision between life and death of liver cells. NF- $\mathrm{KB}$ might play a crucial role in NAFLD development and an inhibitors of NF- $\mathrm{KB}$ might be effective in NAFLD treatment [21].

Vitamin D, a well-known steroid hormone that regulates mineral metabolism, has emerged as a promising hepatoprotective agent and considerable attention to the beneficial effect of vitamin $\mathrm{D}$ in NAFLD treatment had been reported. Accumulating data suggested that the blood level 
of $25-\mathrm{OH}$ vitamin $\mathrm{D}$ was negatively correlated with the risk of liver insult $[22,23]$. .The pivotal role of vitamin $\mathrm{D}$ was more evidenced when reports indicating that vitamin $\mathrm{D}$ deficiency (VDD) in humans and animals contributes to the development of NAFLD [24]. It was found by Manco et al., [25] that low levels of $25(\mathrm{OH}) \mathrm{D}$ was associated with significant increase in NAFLD Activity Score (NAS) and fibrosis in children with biopsy-diagnosed NAFLD. Several publications in recent years documenting the possible beneficial role of vitamin $\mathrm{D}$ in the management of NAFLD while the underlying mechanisms needs further clarification [26].

Modulation of PPAR- $\alpha$ by 1, $25(\mathrm{OH}) 2$ D3 was reported in diabetic rat model both in cardiac tissue [27] and liver tissue [28], while modulation of PPAR- $\alpha$ and its target gene (NFKBIA) by vitamin D3 in a rat model of NASH induced by HCHFD has not been studied yet. Therefore, this work aimed to evaluate whether vitamin D could alleviate NASH model in rats induced by high carbohydrate high fat (HCHF) diet, and to clarify if modulation of genes expression of PPAR- $\alpha$ and NFKBIA by vitamin $D$ could be a potential mechanism.

\section{Mate rials and methods}

\section{Chemicals:}

D-fructose:

D-fructose was purchased from (EL-Gomhoria Company industries, Egypt) in the form of white powder (240 gm). A concentration of fructose $25 \%$ in drinking water was prepared every other day [29] ,by dissolving $25 \mathrm{~g}$ of fructose in a volume of $100 \mathrm{ml}$ tap water in bottles, after that aluminum foil was used to cover the bottles to avoid fructose fermentation [30], then this preparation was administered daily for eight weeks.

Vitamin D3 (1, $25 \mathrm{Di}-\mathrm{OH}$ cholecalciferol):

Vitamin D3 (1,25 Di OH cholecalciferol ) was purchased from Memphis (Memphis ,Egypt) as Devarol-S (2ml/amp.5mg =200.000 I.U) (diluted in $0.9 \%$ sodium chloride to get final concentration of $0.5 \mu \mathrm{g} / 1 \mathrm{ml})$ [31].

\section{Animals}

Experimental animals and diet:

This study was conducted on 30 male SpragueDawley rats, (weight, 200-250 gm) obtained from the Mansoura Experimental Research Center (MERC), then, rats were housed 5 per cage at normal atmospheric temperature with a 12-hour light-dark cycle at Department of Physiology, Mansoura Faculty of Medicine. Animals fed rat chow and had free access to tap water for 4 weeks to be familiarized with the new environment.

The animals care was conducted according to the Guide to the Care and Use of Laboratory Animals (1996, published by National. Academy. Press., 2101 Constitution Ave. N.W., Washington, DC20055, and USA). All procedures of the experimental study were conducted in accordance to the guidelines of local ethical committee of Mansoura Faculty of Medicine.

\section{Experimental design and animal grouping:}

After an initial acclimatization for a period of four weeks, the rats were randomly divided into three groups of equivalent number as follow: Group I (negative control group) fed normal fat diet (NFD) with $15 \%$ of its calories derived from 
fat and it was prepared in accordance to AIN-93G rodent diet [32] and had free access to plain water plus administration of saline $(1 \mathrm{ml} / \mathrm{kg})$ twice weekly by the I.P. route. Group II (positive control or NASH group) fed HCFD of which ; HFD was similar in composition to NFD, except for addition of $200 \mathrm{gm}$ beef fat $/ \mathrm{kg}$ to make percent of calories derived from fat $45 \%$ [32] and received $25 \%$ fructose-sweetened water for 8 weeks [33], plus administration of saline $(1 \mathrm{ml} / \mathrm{kg})$ twice weekly by the I.P. route .Group III (Vitamin D3 treated NASH group) received HCHFD as group II and after 4 weeks received treatment in the form of I.P. injection of 1,25VD3 with a dosage of $5 \mu \mathrm{g} / \mathrm{kg}$ body weight twice weekly till the end of the study.

The rats were weighed every week to adjust then the dosage of vitamin D3 according to body weight changes to maintain constant vitamin D3 dose throughout the entire experiment.

\section{Collection of blood and tissue sampling:}

One day before the end of the experiment, all rats were subjected to 12-hour overnight fasting then in the morning of the following day; all rats were weighed then under thiopental anesthesia at a dose of $75 \mathrm{mg} / \mathrm{kg}$ I.P. injection [34], blood samples were drawn by cardiac puncture then placed into a set of tubes without an anticoagulant then serum from the samples were acquired by centrifugation at $3000 \mathrm{x} \mathrm{g}$ for 20 minutes at $4^{\circ} \mathrm{C}$ and stored at -70 ${ }^{\circ} \mathrm{C}$ until the time of analysis. . After that, the anterior abdominal wall was opened and the livers were excised and weighed then divided into two parts; one part placed in plastic cassettes and sunken in neutral buffered formalin for one day for histopathological examination, the second part was perfused with saline and stored at liquid nitrogen for Oil red $\mathrm{O}$ stain, biochemical assay of markers of oxidative stress and for RT-PCR.

\section{Biochemical analysis:}

Liver function tests:

Serum ALT, AST activities, alkaline phosphatase and serum albumin were measured using (Bio Systems S.A, Spain) kits, and serum bilirubin was measured using (Fortress diagnostic, UK) kits according to manufacturer's instructions.

Total cholesterol (TC) and Triacylglycerol (TAGs):

Were measured by using enzymatic-colorimetric methods (Centrronic GmbH., Germany).

Assay of markers of oxidative stress in liver tissues:

Parts of liver tissues of about 50-100 mg were homogenized in 1-2 $\mathrm{ml}$ cold buffer (composed of $50 \mathrm{mM}$ potassium phosphate, $1 \mathrm{mM}$ EDTA and its $\mathrm{pH}$ was adjusted to be about 7.5) using mortar and pestle, after homogenization ;centrifugation occurred at a speed 4,000 rpm for duration of about 15 minutes with temperature adjusted at $4^{\circ} \mathrm{C}$. then the supernatant was collected and stored at $-20^{\circ} \mathrm{C}$ until the time of analysis ,after that colorimetric method was used to measure the level of Malondialdhyde (MDA), superoxide dismutase (SOD) and reduced glutathione (GSH) activity in the supernatant of liver homogenates in accordance to the manufacturer's instructions (Bio-Diagnostics company, Dokki , Giza, Egypt). 
Assessment of PPAR- $\alpha$ and NFKBIA genes expression in liver tissues by real-time PCR RNA extraction and cDNA synthesis

TotalRNA was extracted from collected liver tissues (30 mg) according to the manufacturer's guidlines ( RNeas y mini kit. , Qiagen. , Hilden., Germany), then Nano Photometer P-330 (Munchen ,Germany) was used to measure RNA concentration and quality ,after that; SensiFAST TM cDNA Synthesis Kit (Bioline, UK) was used to reverse transcript one mg of RNA . Real-time PCR was done with a $20 \mu \mathrm{L}$ total reaction volume containing cDNA of volume $4 \mu \mathrm{L}$ and $1 \mu \mathrm{L}$ for each primer pair and a volume of $10 \mu \mathrm{L}$ of SYBR green ( SensiFAST TM SYBR ® NO-ROX kit; Bioline, UK) . RTPCR primers used in this work are listed in Table 1. Act-b was used as an endogenous control that NFKBIA and PPAR- $\alpha$ mRNA levels were adjusted as the values compared to it, PikoReal TM RealTime PCR system (Finland) was used to perform PCR.

\section{5-Histopathological study}

Formalin fixed liver specimens were dehydrated using graded alcohol solutions then embedded in paraffin. The five-micron thick paraffin sections were cut and slides were stained with (i) hematoxylin and eosin for histopathological analysis (ii) Masson trichrome for assessment of fibrosis (iii) Oil Red $\mathrm{O}$ staining, and (iv)

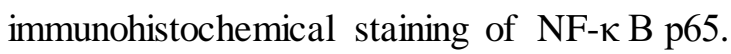

\section{Oil Red $O$ staining:}

Liver tissues, which were frozen in optimum cutting temperature compound, were cut at thickness of $5 \mu \mathrm{m}$, then mounted on slides and left for 1-2 hours to dry then $10 \%$ formalin was used to fix theses sections for a duration of $10 \mathrm{~min}$, after that they were rinsed with PBS (PH 7.4), at that point slide were left till dry, after that the slides were set in $100 \%$ propylene glycol for term of 2 min then stained in $0.5 \%$ Oil Red $\mathrm{O}$ solution for around $30 \mathrm{~min}$, after that they were transferred to an propylene glycol solution of conc. of $85 \%$ for 1 min. then rinsed in distilled water for 2 times, and lastly hematoxylin was used as a counter stain.

Scoring of NASH:

Histological examination was performed using NAFLD activity score (NAS) which is the total score resulting from the sum of individual scores of steatosis $(0-3)$, lobular inflammation $(0-2)$, and hepatocellular ballooning (0-2). NASH was diagnosed if rats have total score of $\geq 5$ [35].

Immunohistochemical staining and assessmentfor NF-к B p65:

Serial sections $(5 \mu \mathrm{m})$ were deparaffinized, rehydration and antigen retrieval was performed in the PT Link (Dako PT100), the then slides were processed utilizing an automated staining protocol on the Autostainer Link 48 (Dako AS480) using NF-kB/p65 Ab-1 (Cat. \#RB-9034-R7, Neomarkers, Labvision, Fremont, California, USA).

Semi-quantification of positive cells by immunohistochemistry

The number of NF- $\kappa$ B p65 positive cells was counted in 30 random high-power fields the NF$\kappa \mathrm{B}-\mathrm{p} 65$ positive cells were calculated by counting manually the cells with NF- $\mathrm{BB}$-positive nuclei [36]. 


\section{6- Statistical analysis:}

SPSS version 16.0 was used for statistical analysis. One way analysis of variance (ANOVA) for quantitative data with Tukey's post hoc analysis was used for multiple group comparisons. Mean \pm standard deviation (mean $\pm \mathrm{SD}$ ) was used for quantitative data .Pearson's rank test was performed to determine correlation between all study cases together (not group by group). A probability level $\mathrm{p}$ of $\leq 0.05$ indicates a significant statistical difference.

Table (1): Sequences of primers for Quantitative RT-PCR

\begin{tabular}{|l|c|c|c|c|}
\hline Gene & $\begin{array}{c}\text { GeneBank } \\
\text { Accession No. }\end{array}$ & Forward sequence & Reverse sequence & $\begin{array}{c}\text { Expected } \\
\text { product } \\
\text { size(bp) }\end{array}$ \\
\hline NfKBIA & NM_001105720.2 & CCCAAGTACCCGGATACAGC & GGGCAACTCATCTTCCGTGA & 1583 \\
\hline PPAR-a & NM_013196.1 & TCCTCTGGTTGTCCCCTTGA & CAGTCTTGGCTCGCCTCTAA & 2022 \\
\hline Act-b & NM_031144.3 & CACCATGTACCCAGGCATTG & CACACAGAGTACTTGCGCTC & 1293 \\
\hline
\end{tabular}

PPar- $\alpha$, Rattus norvegicus peroxisome proliferator activated receptor alpha, NfkBIA, Rattus norvegicus nuclear factor of kappa light polypeptide gene enhancer in B-cells inhibitor, alpha, Act-b, Rattus norvegicus actin, beta

\section{Results}

Effect of 1,25-VD3 on body and liver weight, serum triglycerides and total cholesterol and liver function tests :

Changes in body and liver weight among all groups are shown in Table 2; NASH group fed HCHFD had marked obesity as shown by significant increase in body weight and also significant increase in liver weight when compared to negative control group and these changes in body and liver weight were partially but significantly lowered with $1,25-\mathrm{VD} 3$ treatment but their values were still significantly higher than negative control group.

Serum triglycerides and cholesterol for all studied groups are shown in Table 2; NASH group showed hyperlipidemia in the form of significant elevation of serum triglycerides, total cholesterol, when compared to negative control group $(\mathrm{p}<\mathbf{0 . 0 0 0 1})$ and these metabolic disturbances were partially but significantly lowered with $1,25-\mathrm{VD} 3$ treatment but their values were still significantly higher than negative control group.

Liver function tests are shown in (Table 2).; showing significant elevation of serum liver enzymes (ALT,AST and alkaline phosphatase) in NASH group when compared to negative control group and the group treatment with 1,25-VD3 exhibited significant reduction of liver enzymes but still higher than negative control group. Compared with the negative control group, there was significant elevation of serum bilirubin in in NASH group and this level was decreased significantly with $1,25-\mathrm{VD} 3$ treatment; however in all groups; serum bilirubin was still within normal range, moreover ,no significant differences were observed for serum albumin levels in all studied groups $(P>0.05)$. 
Effects of 1,25-VD3 on liver tissue oxidative stress markers :

The alterations of oxidative stress markers in liver tissue are shown in Table 3 , showing significant increase in hepatic MDA level with concomitant significant depletion in antioxidant system as depicted by decline in GSH and sodium oxide dismutase (SOD) level in NASH group compared to negative control group $(\mathrm{p}<0.01)$. On the other hand 1,25-VD3 treated groups partially corrected this oxidative stress by increasing hepatic level of GSH and SOD accompanied by significant decrease in MDA concentration as compared to NASH group $(\mathrm{p}<0.01)$.

Effects of 1,25-VD3 on liver histology and NAFLD score:

As illustrated in Fig.1 ,H\&E-stained sections; negative control group displayed intact lobular architecture with cord like arrangement of hepatocytes (Fig.1 A1), with no obvious hepatic steatosis, hepatocellular ballooning and minor foci of inflammatory cells (Fig.1 A2), However, in group HCHFD rats ,there was abnormal structure of hepatic lobule (Fig.1 B1),marked macrovesicular steatosis ,ballooning and mild to moderate lobular inflammation (Fig.1 B2);their NAS scores were significantly elevated in NASH group $(6.1 \pm 0.56)$ while treatment with vitamin D3 decreased markedly steatosis ,ballooning and inflammation (Fig.1 $\mathrm{C} 1$ and $\mathrm{C} 2$ ) with significant decrease in mean NAS scores to $(2.8 \pm 0.78)$.

As regard to Oil Red O staining, there were small scattered lipid droplets $(<5 \%)$ in few liver cells of negative control group (Fig.1 A5). In contrast, liver cells of NASH group were of different sizes and full of lipid droplets (Fig.1 B5), while vitamin D treated group shows diffuse distribution but fewer lipid droplets of hepatocytes when compared with NASH group (Fig.1 C5).

As illustrated in Fig. 1; (Masson's trichrome staining), there was no obvious fibrosis (indicated by blue coloration) in negative control group (Fig.1 A3). While, some rats showed fibrosis around sinusoidal spaces and in the portal area with bridging fibrosis in group HCHFD (Fig.2 B3), the group receiving vitamin D treatment has lower level of fibrosis than that of HCHFD group (Fig.1 C3).

Effect of 1,25-VD3 on expression of hepatic NFB p 65:

Immunohistochemistry staining of NF- $\kappa$ B p65 are shown in (Fig1 A4, B4 and C4). indicating upregulation of NFK- $\beta$ p65 in NASH group in the form of obvious brownish nuclear staining and increased brownish cytoplasmic staining when compared with negative control group which showed weakly positive brownish staining in liver tissue and nearly no nuclear staining and treatment with vitamin D3 significantly down regulated this hepatic NF- $\kappa$ B p65 protein expression as evidenced by decrease in nuclear staining but that was accompanied by an increase in brownish cytoplasmic staining.

Effect of 1,25-VD3 on mRNA expression of PPAR$\alpha$ and NFKBIA in liver tissue:

Group fed HCHFD were found to have significant decrease in mRNA expression of PPAR- $\alpha$ (Fig.2) and NFKBIA (Fig.3) as compared to negative control group $(\mathrm{p}<0.0001)$. Meanwhile; the 1,25 - 
VD3 treatment group showed significant up regulation, of mRNA expression of PPAR- $\alpha$ and
NFKBIA $(\mathrm{p}<0.0001)$ when compared to HCHFD group.

Table 2: Effects of treatment with Vitamin D on body weight, liver weight, serum triglycerides, total cholesterol and some liver function tests

\begin{tabular}{|l|c|c|c|c|}
\hline Groups & $\begin{array}{c}\text { Group I } \\
\mathbf{n}=\mathbf{1 0}\end{array}$ & $\begin{array}{c}\text { Group II } \\
\mathbf{n = 1 0}\end{array}$ & $\begin{array}{c}\text { Group III } \\
\mathbf{n = 1 0}\end{array}$ & $\begin{array}{c}\text { One way } \\
\text { ANOVA }\end{array}$ \\
\cline { 1 - 3 } Variables & & & & p-value \\
\hline Body weight (gm) & $414.2 \pm 13.62$ & $507.7 \pm 17.86^{\mathrm{a}}$ & $453.1 \pm 18.04^{\mathrm{a}, \mathrm{b}}$ & $<0.0001^{*}$ \\
\hline Liver we ight (gm) & $11.0 \pm 1.23$ & $13.93 \pm 0.67^{\mathrm{a}}$ & $12.6 \pm 0.92^{\mathrm{a}, \mathrm{b}}$ & $<0.0001^{*}$ \\
\hline $\begin{array}{l}\text { Serum triglyce ride } \\
\text { levels (mg/dl) }\end{array}$ & $54.22 \pm 8.63$ & $119.54 \pm 8.58^{\mathrm{a}}$ & $75.6 \pm 15.30^{\mathrm{a}, \mathrm{b}}$ & $<0.0001^{*}$ \\
\hline $\begin{array}{l}\text { Serum total choles te rol } \\
\text { levels (mg/dl) }\end{array}$ & $50.51 \pm 14.30$ & $111.07 \pm 16.71^{\mathrm{a}}$ & $72.594 \pm 8.39^{\mathrm{a}, \mathrm{b}}$ & $<0.0001^{*}$ \\
\hline Serum AST(IU/L) & $76.53 \pm 6.46$ & $234.9 \pm 55.81^{\mathrm{a}}$ & $114.14 \pm 12.08^{\mathrm{b}}$ & $<0.0001^{*}$ \\
\hline Serum ALT(IU/L) & $51.31 \pm 7.60$ & $101.03 \pm 16.20^{\mathrm{a}}$ & $66.66 \pm 11.95^{\mathrm{a}, \mathrm{b}}$ & $<0.0001^{*}$ \\
\hline $\begin{array}{l}\text { Serum Alkaline } \\
\text { phosphatase (IU/L) }\end{array}$ & $149.96 \pm 29.28$ & $343.15 \pm 49.95^{\mathrm{a}}$ & $238.07 \pm$ & $<0.0001^{*}$ \\
\hline $\begin{array}{l}\text { Serum albumin } \\
\text { levels (mg/dl) }\end{array}$ & $3.01 \pm 0.33$ & $4.03 \pm 0.65^{\mathrm{a}}$ & $4.02 \pm$ & $<0.0001^{*}$ \\
\hline $\begin{array}{l}\text { Serum total bilirubin } \\
\text { levels (mg/dl) }\end{array}$ & $0.24 \pm 0.01$ & $0.36 \pm 0.04^{\mathrm{a}}$ & $0.30 \pm 0.06^{\mathrm{a}, \mathrm{b}}$ & $<0.0001^{*}$ \\
\hline
\end{tabular}

Values are expressed as mean $\pm \mathrm{SD}$. $* \mathrm{P}$ was considered significant at $<0.05$; a Significance vs control group , b Significance vs NASH induced group using One way ANOVA followed by Tukey's post hoc test for multiple comparison. ALT alanine aminotransferase, AST aspartate aminotransferase.

Table 3: Effects of treatment with Vitamin D on liver tissue oxidative stress markers PPAR- $\alpha$ and NFKBIA mRNA expression and NAFLD activity score:

\begin{tabular}{|c|c|c|c|c|}
\hline Groups & \multirow[t]{2}{*}{$\begin{array}{c}\text { Group I } \\
\mathbf{n}=\mathbf{1 0}\end{array}$} & \multirow[t]{2}{*}{$\begin{array}{c}\text { Group II } \\
n=10\end{array}$} & \multirow[t]{2}{*}{$\begin{array}{c}\text { Group III } \\
\mathbf{n}=10\end{array}$} & $\begin{array}{l}\text { One way } \\
\text { ANOVA }\end{array}$ \\
\hline Variables & & & & p-value \\
\hline $\begin{array}{l}\text { Liver tiss ue MDA } \\
\text { (nmol/mg protein/ml) }\end{array}$ & $\begin{array}{l}86.82 \pm \\
10.76\end{array}$ & $\begin{array}{l}279.21 \pm \\
25.73^{\mathrm{a}}\end{array}$ & $\begin{array}{l}148.84 \pm \\
53.77^{\mathbf{a}, \mathbf{b}}\end{array}$ & $<0.0001 *$ \\
\hline $\begin{array}{l}\text { Liver tiss ue SOD } \\
\text { Activity units/mg } \\
\text { protein }\end{array}$ & $\begin{array}{c}649.76 \pm \\
38.01\end{array}$ & $\begin{array}{l}344.18 \pm \\
72.59^{\mathrm{a}}\end{array}$ & $\begin{array}{l}547.06 \pm \\
79.26^{\mathbf{a}, \mathbf{b}}\end{array}$ & $<0.0001 *$ \\
\hline $\begin{array}{l}\text { Liver tissue GSH (mg/ } \\
\text { g liver tissue) }\end{array}$ & $90.63 \pm 10.45$ & $35.15 \pm 24.25^{\mathrm{a}}$ & $78.14 \pm 12.58^{b}$ & $<0.0001 *$ \\
\hline $\begin{array}{l}\text { DNA-binding activity of } \\
\text { liver NFKBIA }\end{array}$ & $1.0 \pm 0.00$ & $0.26 \pm 0.03^{\mathrm{a}}$ & $0.63 \pm 0.06^{\mathrm{a}, \mathrm{b}}$ & $<0.0001 *$ \\
\hline $\begin{array}{l}\text { DNA-binding activity of } \\
\text { liver PPAR } \alpha\end{array}$ & $1.0 \pm 0.00$ & $0.441 \pm 0.05^{\mathrm{a}}$ & $0.72 \pm 0.07^{\mathrm{a}, \mathrm{b}}$ & $<0.0001 *$ \\
\hline NAFLD score & $0.2 \pm 0.4$ & $6.1 \pm 0.56^{\mathrm{a}}$ & $2.8 \pm 0.78^{\mathbf{a}, \mathbf{b}}$ & $<0.0001 *$ \\
\hline
\end{tabular}

Values are expressed as mean $\pm \mathrm{SD}$. $* \mathrm{P}$ was considered significant at $<0.05$; a Significance vs control group , b Significance vs NASH induced group using One way ANOVA followed by Tukey's post hoc test for multiple comparison. MDA; malondialdehyde, GSH; glutathione, SOD; superoxide dismutase, PPAR $\alpha$; peroxisome proliferatoractivated receptor alpha ,NFKBIA; nuclear factor-kappa-B inhibitor subunit-alpha 


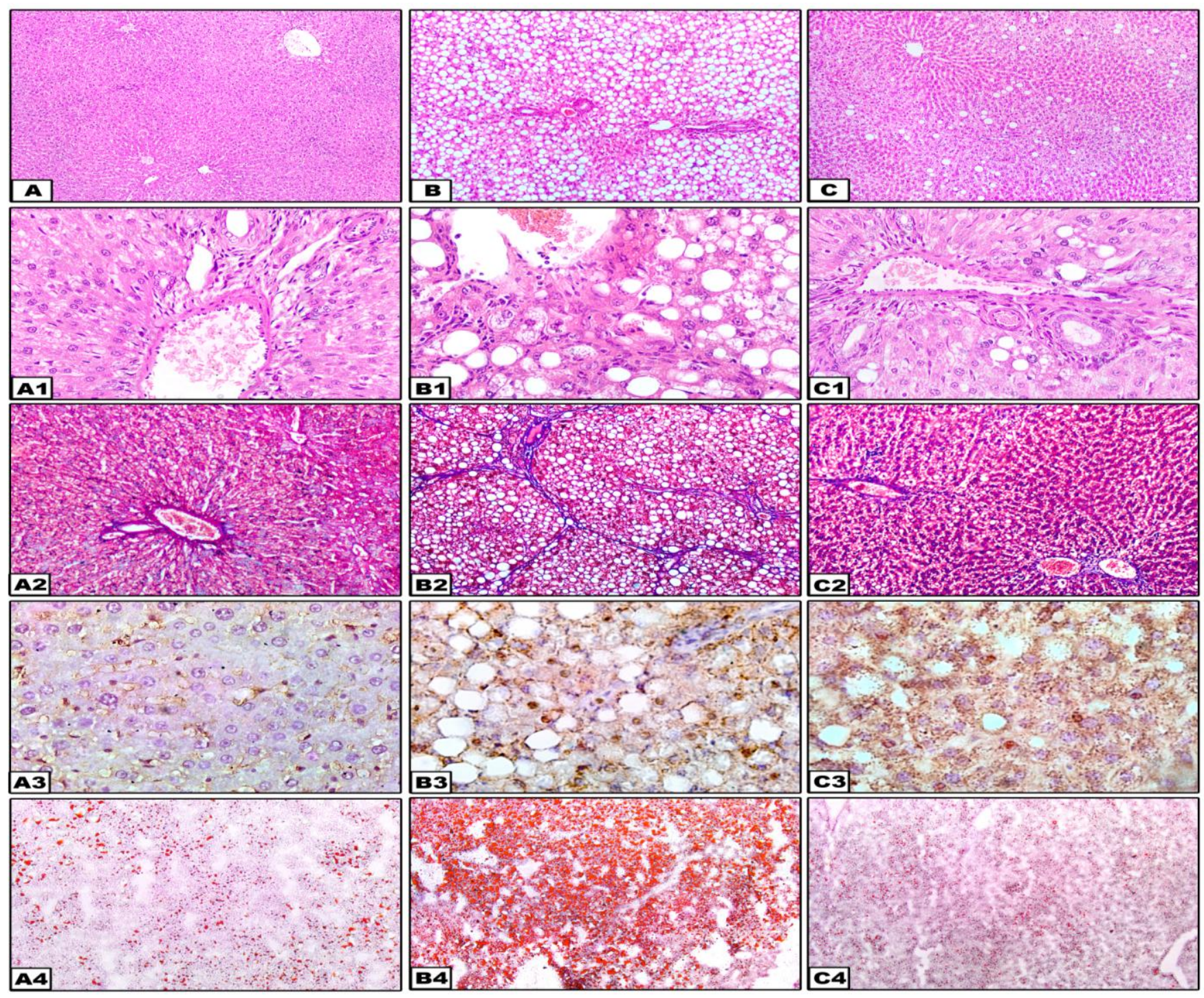

Fig. 1 Effects of vitamin $\mathbf{d} 3$ therapy on NASH: Photo micrograph of (A) negative control group (B) NASH group (C)Vitamin D3 treated group ;(100x). Sections stained with hematoxylin and eosin (1), (400x) Sections stained with hematoxylin and eosin (2), Masson trichrome stain (3),Immunohistochemistry of NFK $\beta-p 65$ (4)Oil red O staining (5).-Negative control group; showed intact hepatic lobule with cord like cell arrangement (A1) no steatosis, ballooning or inflammation (A2) slight or no fibrosis by masson trichrome (A3) small scattered lipid droplets $(<5 \%)$ in hepatocyte by Oil O red stain (A5), while NASH group showed distorted hepatic lobule (B1) marked macrovesicular and micro vesicular steatosis ,ballooning with mild to moderate lobular inflammation (B2) perivenular fibrosis with formation of fibrous septa by masson trichrome (B3) marked increase in size and distribution of lipid droplets inside hepatocytes by Oil red O stain (B5),Vitamin D3 treated group showed some preservation of hepatic lobule (C1) significant decrease in steatosis , ballooning with mild lobular inflammation (C2) perivenuar fibrosis without formation of fibrous septa by masson trichrome (C3) diffuse distribution but fewer lipid droplets of hepatocytes by Oil red $\mathrm{O}$ stain (C5).-Immunohistochemical staining of NFK- $\beta$; NASH group showed nuclear staining and increased brownish cytoplasmic staining (B4) when compared with negative control group which showed weakly positive brownish staining and nearly no nuclear staining (A4) and treatment with vitamin D3 significantly decreases this brownish staining of nuclei (C4).

As regard correlation between NAS score as independent variable and PPAR- $\alpha$ or NFKBIAas dependent variable table (4) and figures $(4,5$ and 6) show the following:

There was negative correlation between NAS score and PPAR- $\alpha$ or NFKBIA $(\mathrm{P}<0.001)$. On the other hand, there was positive correlation between PPAR- $\alpha$ level and NFKBIA in liver tissue $(\mathrm{P}<0.001)$. 


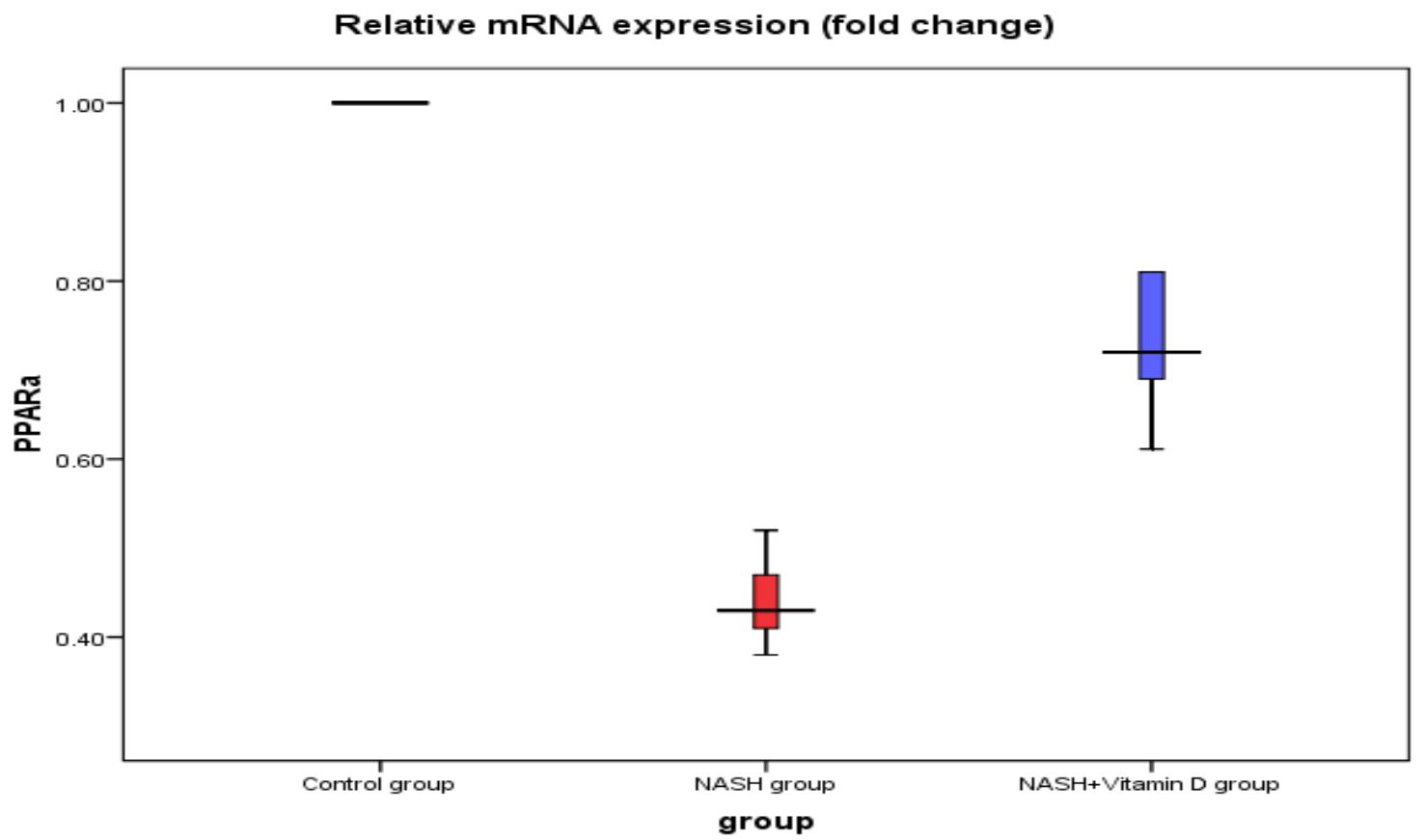

Fig. 2. Liver tissue PPAR- $\alpha$ levels. Values are expressed as mean \pm SD. $* P$ was considered significant at $<0.05$; a significant as compared to the control group, b significant as compared to NASH group using One way ANOVA followed by Tukey's post hoc test for multiple comparison.

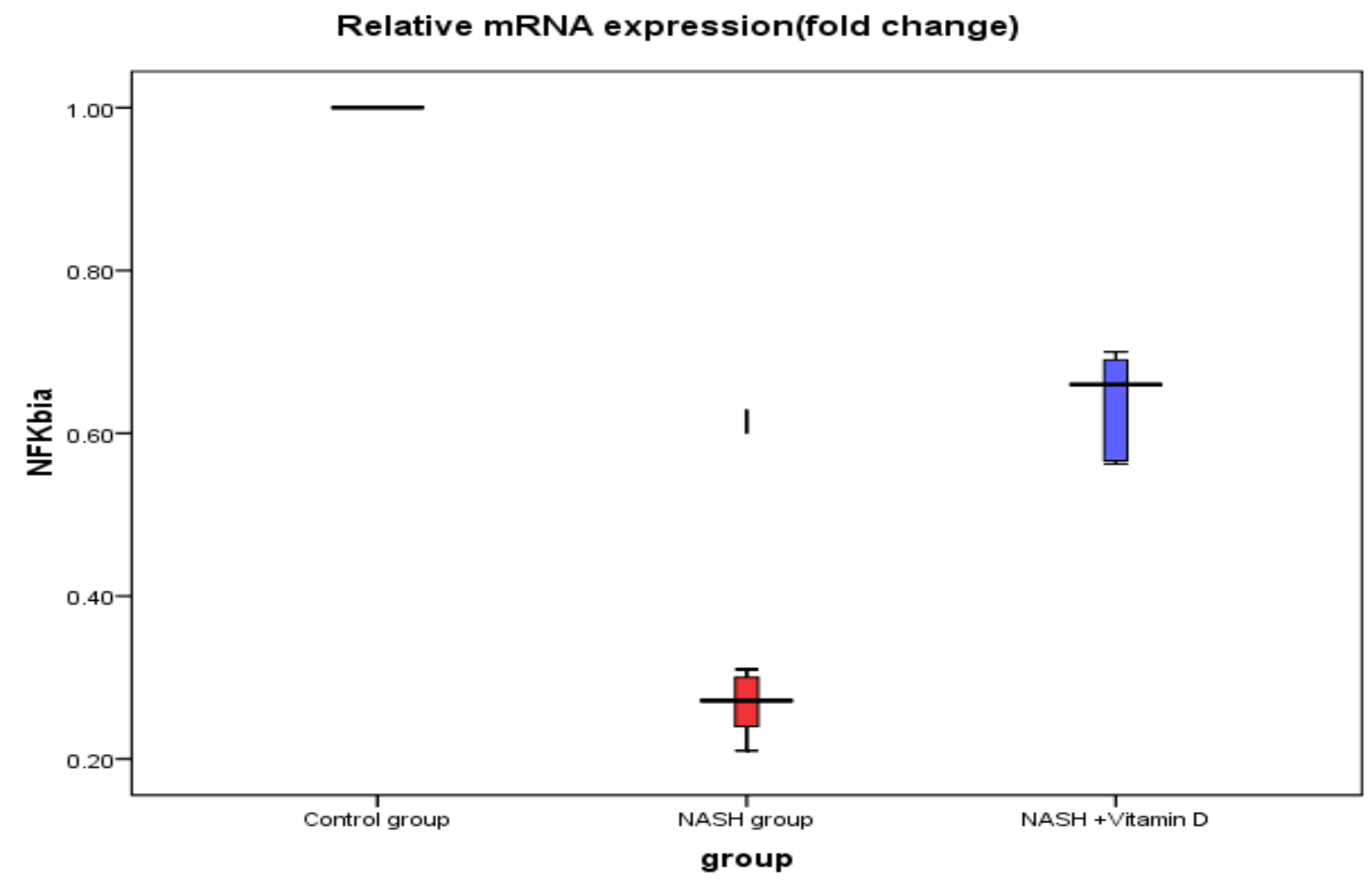

Fig. 3. NFKBIA mRNA relative expression. Values are expressed as mean $\pm \mathrm{SD}$. ${ }^{*} \mathrm{P}$ was considered significant at $<0.05$; a significant as compared to the control group, b significant as compared to NASH group using One way ANOVA followed by Tukey's post hoc test for multiple comparison. 
Table (4): Pearson correlation between NAS score as independent variable and PPAR- $\alpha$ or NFKBIA as dependent variable:

\begin{tabular}{|c|c|c|c|c|}
\hline \multirow{3}{*}{ NAS score } & \multicolumn{2}{|c|}{ PPAR- $\alpha$} & \multicolumn{2}{|c|}{ NFKBIA } \\
\hline & $\boldsymbol{R}$ & Pvalue & $\boldsymbol{R}$ & P value \\
\hline & -0.808 & $P<0.001$ & -0.797 & $P<0.001$ \\
\hline PPAR- $\alpha$ & & & 0.934 & $P<0.001$ \\
\hline
\end{tabular}

Pearson correlation (significance at $\mathrm{p} \leq 0.05$ ). $\mathrm{r}=$ reflection coefficient.NAS $=$ NAFLD activity score. PPAR- $\alpha$ $=$ peroxisome proliferator-activated receptors alpha. NFKBIA $=$ nuclear factor-kappa-B inhibitor subunitalpha

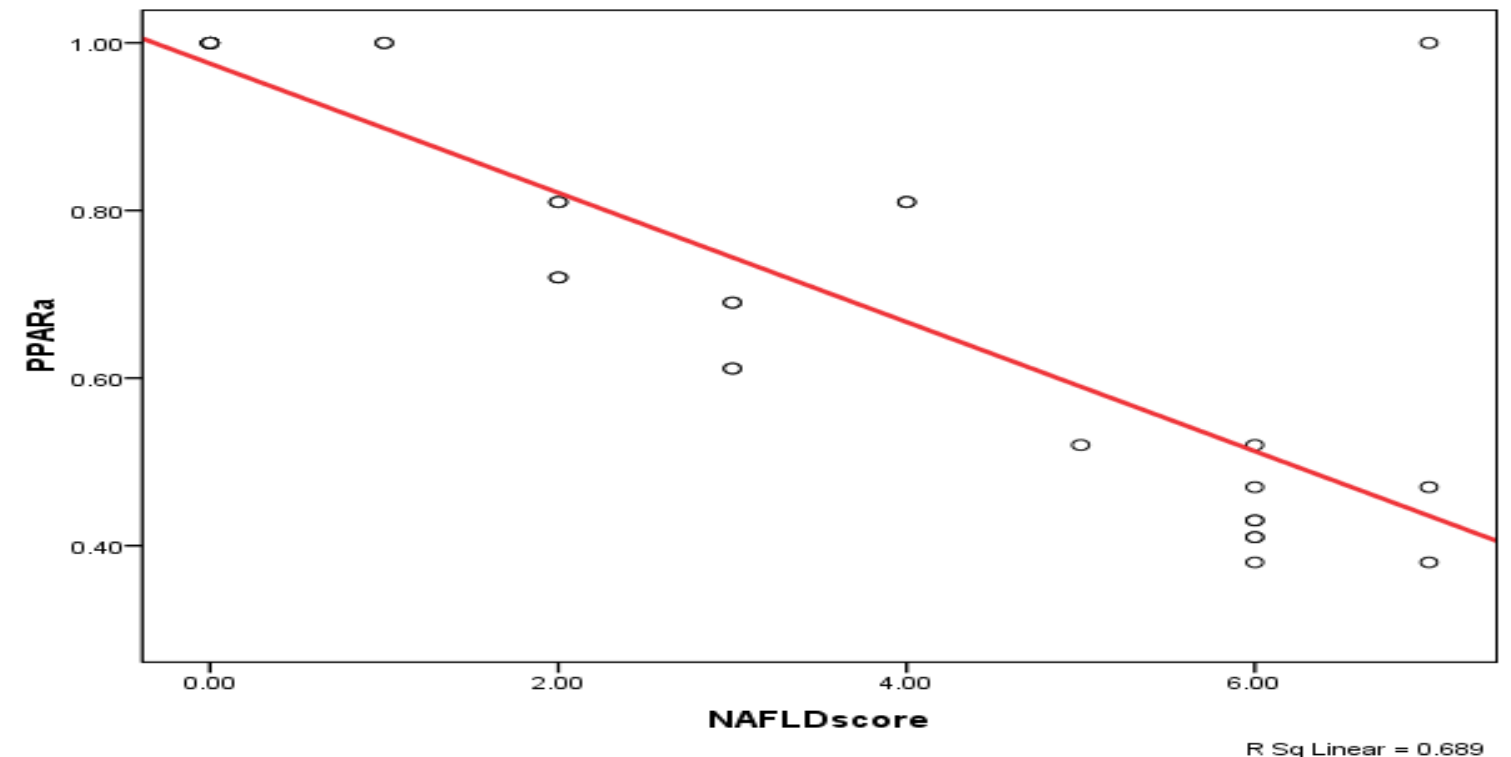

Fig. 4. Pearson correlation between NAFLD score and relative mRNA expression of. PPAR- $\alpha$

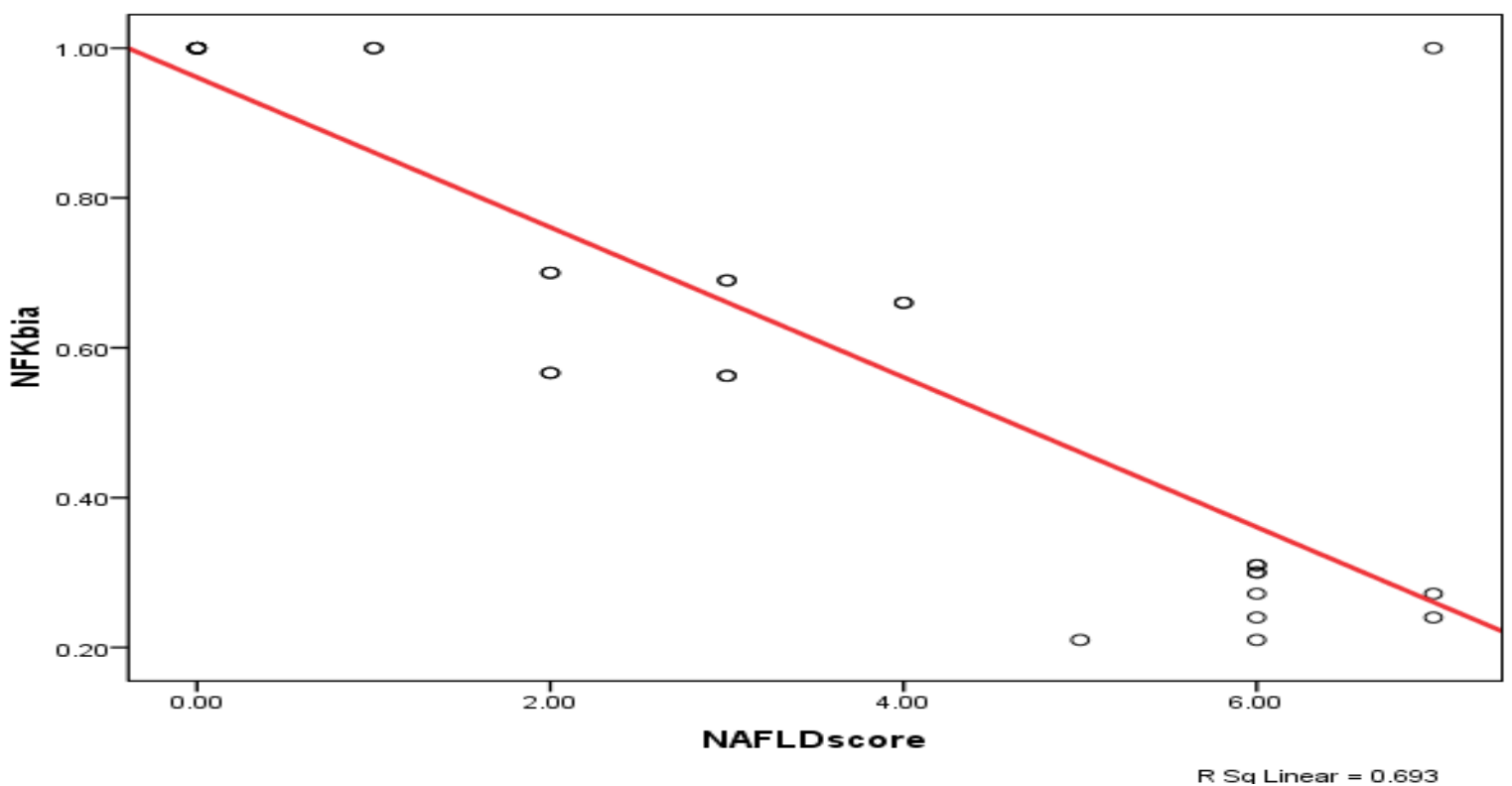

Fig. 5. Pearson correlation between NAFLD score and relative mRNA expression of NFKBIA.

progress to cirrhosis, liver failure and

\section{Discussion:}

NAFLD is the commonest cause of chronic liver disease, constituting a major risk factor that could hepatocellular carcinoma [37, 38, 39]. The disease is so dangerous that the National Institutes of Health refers to it as a "silent disease" [40]. 
Therefore, there is an unmet need to choose an appropriate animal model of NASH and to fully clarify the underlying mechanisms of NASH and consequently develop new approach for treatment or intervention of disease progression.

In the present, the HCHFD was chosen to understand the potential beneficial mechanisms of vitamin D3 on NASH associated changes, because the addition of the high fructose content to a high fat diet had been reported to reproduce all the features of NASH [41]. Fructose can promote de novo lipogenesis, contributing to first hit and also promote inflammation through endogenous toxins of fructose metabolites thus contributing also to the second hit of the pathogenesis of NASH [42].

Moreover, these animals displayed a NASH like phenotype similar to human NASH with significant increase in hepatic reactive oxygen species (ROS) [43] , Furthermore, a study by Ishimoto et al., [44] showed that with mice administration of sucrose with high-fat foods leads to a synergistic effect that may induce liver inflammation and fibrogenesis .

In the current study, rats fed HCHFD for eight weeks showed significant hyperlipidemia in the form of elevated serum triglycerides and total cholesterol ,elevation of liver enzymes ,but with no significant difference in serum albumin or bilirubin; Furthermore, histological examination of liver showed typical changes found in NAFLD in the form of marked steatosis ,ballooning and foci of inflammatory infiltrate with average NAS score of $(6.1 \pm 0.56)$ with fibrosis in the some rats however fibrosis not rich significant level, these histological changes were associated with significant elevation of hepatic oxidative stress parameters, increased NF- $\kappa$ B-p65 expression and decreased expression of PPAR $\alpha$ and NFKBIA, Alteration in biochemical parameters combined with pathologic features of the liver, indicates that the experimental preparation of NASH rat model using HCHFD in the present work was successful.

Accumulation of lipids inside hepatocytes is considered as the 'first hit' in the 'two-hit theory' assumed by Day and Jones, [4]. In the present study, steatosis was confirmed by histolopathological examination under light microscope either by H\&E showing Marked macro vesicular and micro vesicular steatosis or Oil $\mathrm{O}$ red stain showing significant increase in distribution of hepatocyte which were full of lipid droplet of different sizes, in addition to these histopathological changes there were concomitant hyperlipidemia in NASH-induced group in the form of significant increase in serum triglycerides and total cholesterol.

Lipid accumulation in the hepatocytes in our work could be attributed to two mechanisms; (i) excessive fatty acids uptake which is achieved in present work through high fat diet and de novo lipogenesis in liver [45] which is achieved also in the present work through fructose consumption [41]; fructose metabolism in the liver increases cholesterol biosynthesis [46] and activates enzyme that catalyzes the final step in TG synthesis [47] (ii) The other mechanism of steatosis is impaired beta fatty acid oxidation [12]. PPAR- $\alpha$ is the nuclear which is the nuclear receptors responsible for hepatic lipid metabolism and fatty acid oxidation [48].

In the current work, assessment of PPAR- $\alpha$ gene expression using RT-PCR revealed that there was 
down regulation of PPAR- $\alpha$ in liver tissue of NASH group as compared to negative control group, this finding is in agreement with many investigators ; Mandard et al ., [49] found that there was significant decrease in the expression of hepatic PPAR- $\alpha$ in NAFLD . Ning et al ., [28] found also, down regulation of hepatic PPAR- $\alpha$ in a NASH model of diabetic rat .Treatment with vitamin D3 in the present work resulted in partial correction of hyperlipidemia as shown by significant decrease in serum triglycerides and cholesterol as well as decrease lipid accumulation in the hepatocytes as assessed by histopathological examination.

We assumed that this effect is mediated through PPAR- $\alpha$ pathway and to prove this RT-PCR for mRNA of PPAR- $\alpha$ was done ; we found that there was significant down regulation of hepatic expression of PPAR- $\alpha$ mRNA in the liver cells of NASH group and this down regulation was reversed in the vitamin D3 treated group. This unique role of PPAR- $\alpha$ in correction of lipid abnormality in NASH had been proved by many investigators ; Ning et al., [28] mentioned that there was correction of lipid abnormalities as well as hepatic steatosis by vitamin D3 through increase hepatic PPAR- $\alpha$ gene expression .Also Yin et al.,[26] stated that 1,25(OH)2D3 has a significantly lower serum lipid levels ,decreasing hepatic lipid uptake, hence attenuating steatosis .These above mentioned finding support the therapeutic effect of vitamin D3 through PPAR-a pathway in correction of hyperlipidemia and amelioration of hepatic steatosis which is the first hit in NASH pathogenesis
Interestingly, our data about liver enzymes in the current work revealed that, there was elevation of AST (more than 3 folds) and ALT (nearly 2 folds) and alkaline phosphatase ( 2 folds), indicating that there was a state of hepatic injury [50]. The use of liver enzymes to diagnose severity of NASH is a matter of controversy, Marchesini et al.,[51] and Sorbi et al , [52] mentioned that there is increased levels of transaminases in NAFLD, with ratio of ALT to AST more than one and this classical ratio can be used to distinguish between steatosis of NAFLD and alcoholic fatty liver disease (AFLD), with the latter having by a high AST:ALT ratio; but as NAFLD progress from hepatic steatosis to NASH and hepatic fibrosis ; AST exceeds ALT resulting in increase in ratio AST :ALT , and this is consistent with the finding of our work . Browning et al., [53] stated that the elevated aminotransferases are not sensitive for detection of hepatic steatosis and it may be normal in patients with advanced fibrosis and cirrhosis .Furthermore; Calvaruso and Craxi, [54] stated that normal liver enzymes could exist with underlying hepatic insult and Harrison et al., [55] attributed the difference of basal ALT/AST levels to variation of mouse strains, gender, age, and dietary condition during the experiment such diet ingredient, percent of fat, and duration of experiment

According to the two-hit theory, the transition from simple steatosis to NASH requires the contributors to the second hit such as oxidative stress associated with lipid peroxidation and mitochondrial dysfunction [7] and proinflammatory mediators [5]. 
In line with previous studies $[56,57]$ we found that livers of NASH group had a significant increase in MDA (marker of increased lipid peroxidation) and significant decrease in SOD, and GSH which are considered free radical scavengers; these findings indicate that there was a condition of oxidative stress and provide good proof for the role of this oxidative stress condition in the pathophysiology of NASH. Also, it has been suggested that ROS in that mitochondrial ROS deplete hepatic antioxidants allowing more accumulation of ROS [58]. In the present study, subsequent treatment with vitamin D3 significantly ameliorated oxidative stress as evidenced by lowering MDA level and increased GSH and SOD levels relative to NASH group the antioxidant effect of vitamin D3 had been proved in various experimental models [59, 60, and 61]. Also, Saggese et al., [59] confirmed this effect in diabetic rat through reduction of lipid perioxidation and enhancement of free radical scavengers such as glutathione peroxidase and catalase, besides the antioxidant effect of Vitamin D3 may be also mediated through PPAR- $\alpha$ up regulation as mentioned by

Toyama et al., [62]. Who found that PPAR- $\alpha$ directly upregulated catalase expression, thus alleviating hepatocytes oxidative stress state in a rat model of fibrosis due to thioacetamide.

As regard the effect of Vitamin D3 on oxidative stress in NASH model, Roth et al., [63] stated that NAFLD progression after a high-fat diet was exacerbated by deficiency of vitamin $\mathrm{D}$, through the activation of toll-like receptors, leading to more hepatic inflammation accompanied by increase in oxidative stress parameters. Moreover, in a randomized clinical trial; vitamin D treatment of adults with NAFLD resulted in reduced serum MDA, liver enzymes, ,oxidative stress, and reduced the expression of inflammatory biomarkers [64] Therefore, it may be concluded that beneficial effect of vitamin D3 is at partially mediated through its antioxidant property as a result of PPAR- $\alpha$ up regulation.

The transcription factor NF- $\kappa$ B is responsible for inflammatory, immune and stress response [19] .NF- $\kappa$ B might play crucial role throughout the course of NAFLD [21]. Normally in nonstimulated cells; IkB $\alpha$ (NFKBIA) inhibitory proteins interacts with NF- $\kappa \mathrm{B}$, sequestering it in the cytoplasm and preventing its translocation into the nucleus; thus hindering activation of NF- $\kappa$ B target gene transcription. .In response to cell stimulation, IkBa undergoes degradation, allowing translocation of NF- $\kappa$ B into the nucleus and activation of target genes [65].

We hypothesize that vitamin $\mathrm{D}$ has antiinflammatory effect through regulation NF- $\kappa$ Bp65 expression and to prove this assumption; immunohistochemistry of NF- $\kappa$ B-p65 was done in the present work; which revealed marked increase in nuclear NF-к B-p65 immunohistochemical nuclear brownish staining in hepatocytes in NASH group when compared to negative control group and this indicates increased nuclear NF- $\kappa$ B translocation with subsequently activation of downstream genes and treatment with vitamin D3 decreased this nuclear staining but unexpectedly, this was accompanied by increased granular cytoplasmic staining in hepatocytes. This effect of vitamin D3 on NF- $\kappa$ B-p65 expression could be 
explained by Cohen-Lahav et al., [66]. ,who found that vitamin D had no effect on total protein or mRNA levels of NF- $\kappa$ B -p65 but did decrease its nuclear translocation with concomitant increase cytoplasmic NFkB-p65 levels .

In current work to investigates the underlying mechanisms of inhibition of NF- $\kappa$ B; two parameters were assessed through RT-PCR technique, NFKBIA and PPAR $-\alpha$ mRNA expression; it revealed that in NASH group there was down regulation of both genes and this down regulation was reversed by Vitamin D3 treatment .This inhibition of NF- $\kappa$ B by Vitamin D3 could be attributed to two mechanism ;first up regulation of NFKBIA with subsequent dimerization with NF- $\kappa$ $B$ in cytoplasmic and prevention of nuclear translocation .This finding is in accordance with Cohen-Lahav et al ., [66] ,who mentioned that $1,25(\mathrm{OH}) 2 \mathrm{D} 3$ was shown to up-regulate the inhibitor of $\mathrm{NF \kappa B}(\mathrm{I} \kappa \mathrm{B}-\alpha)$ by increasing mRNA stability and decreasing I $\mathrm{I} B-\alpha$ phosphorylation .The second mechanism is PPAR $\alpha$ up regulation by vitamin D3 which by turn up regulates downstream gene NFKBIA, leading to subsequent inhibition of NF- $\kappa \mathrm{B}$ nuclear translocation ,this finding is in agreement with Larter et al., [67] who stated that treatment with Wy 14643 (a PPAR- $\alpha$ agonist) in diabetic mice with NASH, upregulates NFKBIA and decreased nuclear levels of NF- $\kappa$ B p65 which resulted in decrease in mRNA of TNF- $\alpha$, NCF2 and MCP1 resulting in decrease in the numbers of neutrophils and macrophages. As a limitation of this study; there was no assessment of Vitamin D3 serum level among all experimental groups ;also, vitamin D3 protective effect against fibrosis could not be assessed because there was fibrosis but not occur in all rat and so no significant difference among all groups ; this could be attributed to short duration of study. So ,we suggest future studies with longer duration to assess effect on fibrosis and if there is long term complications of vitamin D3 as a potential therapeutic agent for NAFLD .

\section{Conclusion:}

In summary, the major finding of our study is that HCHFD model of NASH is a perfect model and provides valuable insight into NAFLD pathogenesis and that Vitamin D3 has a beneficial effect against NASH development rat at different levels of the two hit theory, through PPAR $\alpha$ and NFKBIA up regulation which suppress NF- $\kappa$ B signaling pathway; all of these support the protective role of Vitamin D3 in amelioration NASH pathogenic changes.

\section{References:}

1-Chalasani N, Younossi Z, Lavine JE, Diehl AM, Brunt EM, Cusi K, Charlton M, Sanyal AJ; American Gastroenterological Association; American Association for the Study of Liver Diseases; American College of Gastroenterologyh. The diagnosis and management of non-alcoholic fatty liver disease: practice guideline by the American Gastroenterological Association, American Association for the Study of Liver Diseases, and American College of Gastroenterology. Gastroenterology; 142: 15921609, 2012. 
2-Rinella ME .Nonalcoholic fatty liver disease: a systematic review. JAMA 313: 2263-2273, 2015.

\section{3-Wree A, Broderick L, Canbay A, Hoffiman} HM, Feldste in AE. From NAFLD to

$\mathrm{NASH}$ to cirrhosis-new insights into disease mechanisms. Nat Rev Gastroenterol Hepatol; 10:627-636, 2013.

4-Day CP, James OF. Steatohepatitis: a tale of two 'hits'? Gastroenterology;114:842-5, 1998.

5-Diehl AM, Li ZP, Lin HZ, Yang SQ. Cytokines and the pathogenesis of non-alcoholic steatohepatitis. Gut; 54: 303-306, 2005.

\section{6-Begriche K, Igoudjil A, Pess ayre D, Fromenty}

B. Mitochondrial dysfunction in NASH: causes, consequences and possible means to prevent it. Mitochondrion; 6: 1-28, 2006.

\section{7-Bachar E, Ariav Y, Ketzinel-Gilad M, Cerasi}

E, Kaiser N, Leibowitz G. Glucose amplifies fatty acid-induced endoplasmic reticulum stress in pancreatic beta-cells via activation of mTORC1. PLoS One; 4: e4954, 2009.

8-Haider, D.G.,Schindler, K., Schaller, G., Prager, G., Wolzt, M., Ludvik, B. Increased plasma visfatin concentrations in morbidly obese subjects are reduced after gastric banding. J. Clin. Endocrinol. Metab.; 91, 1578-1581, 2006.

9-Tacke, F., Luedde, T., Trautwein, C. Inflammatory pathways in liver homeostasis and liver injury. Clin. Rev. Allergy Immunol.;36, 412, 2009.

\section{0-Zambon A, Gervois P, Pauletto $P$, Fruchart} JC, Staels B. Modulation of hepatic inflammatory risk markers of cardiovascular diseases by PPARalpha activators: clinical and experimental evidence. Arterioscler Thromb Vasc Biol;26:977986, 2006.

11-Stienstra R, Mandard S, Patsouris D, Maass

C, Kersten S, Muller M. Peroxisome proliferator - activated receptor alpha protects against obesityinduced hepatic inflammation. Endocrinology; 148:2753- 2763, 2007.

12-Abdelmegeed MA, Yoo SH, Henderson LE, Gonzalez FJ, Woodcroft KJ, Song BJ. PPAR alpha expression protects male mice from high fat induced nonalcoholic fatty liver. J Nutr;141:603610, 2011.

13-Baldwin AS Jr. The NF- $\kappa$ B and I $\kappa$ B proteins: New discoveries and insights. Annu Rev Immunol 14:649-683, 1996.

14-Ghosh S, May MJ, Kopp EB. NF-к B and Rel proteins: Evolutionarily conserved mediators of immune responses. Annu Rev Immunol 16:225260,1998

15-Urban MB, Schreck R, Baeuerle PA. NFkappa B contacts DNA by a heterodimer of the p50 and p65 subunit. Embo J.10: 1817-1825, 1991.

16-Hayden MS, Ghosh S. Signaling to NFkappaB. Genes Dev; 18: 2195-2224, 2004.

17-Beckmann J. D., Frerman F. E., 'Electrontransfer flavoprotein-ubiquinone oxidoreductase from pig liver: purification and molecular, redox, and catalytic properties," Biochemistry, vol. 24, no. 15, pp. 3913-3921, 1985.

18- Johnson E. F., Hsu M.-H., Savas U., and Griffin K. J., "Regulation of P450 4A expression by peroxisome proliferator activated receptors," Toxicology, vol. 181-182, pp. 203-206, 2002. 
19-Wullaert A, van Loo G, Heyninck K, Beyaert R. Hepatic tumor necrosis factor signaling and nuclear factor-kappaB: effects on liver homeostasis and beyond. Endocr Rev.;28:365-86, 2007.

20-Siebenlist U, Franzoso G, Brown $K$. Structure, regulation and function of NF-kappa B .Annu Rev Cell Biol.10:405-55, 1994.

\section{1-Tan DY, Shi HY, Li CP, Zhong XL, Kang}

M. Effect of nuclear factor- $\kappa \mathrm{B}$ and angiotensin II receptor type 1 on the pathogenesis of rat nonalcoholic fatty liver disease.World $\mathrm{J}$ Gastroenterol.21;21(19):5877-83, 2015.

22-Jablonski KL, Jovanovich A, Holmen J, Targher G, McFann K, Kendrick J, et al. Low 25-hydroxyvitamin D level is independently associated with nonalcoholic fatty liver disease. Nutr Metab Cardiovasc Dis.; 23:792-8, 2013.

\section{3-Rhee EJ, Kim MK, Park SE, Park CY, Baek}

KH, Lee WY, et al. High serum vitamin D levels reduce the risk for nonalcoholic fatty liver disease in healthy men independent of metabolic syndrome. Endocr J.; 60:743-52, 2013.

24-Alvarez JA, Ashraf A. Role of vitamin D in insulin secretion and insulin sensitivity for glucose homeostasis. Int J Endocrinol; 2010: 351385, 2010.

25-Manco M, Ciampalini P, Nobili V. Low levels of 25-hydroxyvitamin D (3) in children with biopsy-proven nonalcoholic fatty liver disease. Hepatology; 51:2229, 2010.

26-Yin Y, Yu Z, Xia M, Luo X, Lu X, Ling W. Vitamin D attenuates high fat diet-induced hepatic steatosis in rats by modulating lipid metabolism. Eur J Clin Invest.; 42: 1189-1196, 2012.

27-Lee TI, Kao YH, Chen YC, Tsai WC, Chung CC, Chen YJ. Cardiac metabolism,

Inflammation, and peroxisome proliferatoractivated receptors modulated by 1,25dihydroxyvitamin D3 in diabetic rats. Int $\mathrm{J}$ Cardiol.; 176:151-7, 2014.

28-Ning, C., Liu, L., Lv, G., Yang, Y., Zhang, Y., Yu, R.,Zhu, J. Lipid metabolism and inflammation modulated by Vitamin D in liver of diabetic rats. Lipids in Health and Disease; 14, 31, 2015.

29-Sánchez-Lozada L. G., Tapia E., Jiménez A., "Fructose-induced metabolic syndrome is associated with glomerular hypertension and renal microvascular damage in rats," American Journal of Physiology—Renal Physiology, 292, 1, F423F429, 2007.

30-Abdulla M. H.,Sattar M. A, Abdullah N. A., Khan M. A. H., Anand Swarup K. R. L., and Johns E. J., "The contribution of $\alpha 1 \mathrm{~B}$ adrenoceptor subtype in the renal vasculature of fructose-fed Sprague-Dawley rats," European Journal of Nutrition, 50, 4, 251-260, 2011.

\section{1-Han H, Cui M, You X, Chen M, Piao X, Jin} G. A role of $1,25(\mathrm{OH}) 2 \mathrm{D} 3$ supplementation in rats with nonalcoholic steatohepatitis induced by choline-deficient diet. Nutr Metab Cardiovasc Dis.; 25(6):556-61, 2015.

32-Reeves PG, Rossow KL, Lindlauf J. Development and testing of the AIN-93 purified diets for rodents: results on growth, kidney 
calcification and bone mineralization in rats and mice. J Nutr; 123(11):1923e31, 1993.

33-Mamikutty N, Thent ZC, Sapri SR, Sahruddin NN, Mohd Yusof MR, Haji Suhaimi F. The establishment of metabolic syndrome model by induction of fructose drinking water in male Wistar rats. BioMed Res. Int.Biomed Res Int.2014:263897, 2014.

\section{4-Damiani C.E.N., Rossoni L.V., Vassallo} D.V. Vasorelaxant effects of eugenol on rat thoracic aorta .Vascular Pharmacology.;40: 59- 66, 2003.

35-Kleiner DE, Brunt EM, Van Natta $M$, Behling C, Contos MJ, Cummings OW, Ferrell LD, Liu YC, Torbenson MS. Design and validation of a histological scoring system for nonalcoholic fatty liver disease. Hepatology. 41:1313-21,2005 .

\section{6-Tang B, Qiao H, Meng F, Sun X.}

Glycyrrhizin attenuates endotoxin- induced acute liver injury after partial hepatectomy in rats. Braz J Med Biol Res. 40(12):1637-46, 2007.

37-Angulo P. Nonalcoholic fatty liver disease. N Engl J Med 2002; 346: 1221-1231.

38-Angulo P, Lindor KD. Non-alcoholic fatty liver disease. J Gastroenterol Hepatol; 17: S186S190, 2002.

39-Caldwell SH, Oelsner DH, Iezzoni JC, Hespendheide EE, Battle EH, Driscoll CJ. Cryptogenic cirrhosis. Clinical characterization and risk factors for underlying disease. Hepatology; 29: 664-9, 1999.

40. Executive Summary of The Third Report of The National Cholesterol Education Program
(NCEP) Expert Panel on Detection, Evaluation, And Treatment of High Blood Cholesterol In Adults (Adult Treatment Panel III). JAMA. 16; 285(19):2486-97, 2001.

41- Lim, J. S., Mietus-Snyder, M., valente, A Schwarz, J. M. \& Lustig, R. H., fructose in the pathogenesis of NAFLD and the metabolic syndrome. Nat. Rev. Gastroenterol. Hepatol. 7, 251-264 .2010.

42-Nomura K, Yamanouchi T. The role of fructose-enriched diets in mechanisms of nonalcoholic fatty liver disease. J Nutr Biochem; 23: 203-208, 2012.

43-Kohli R., M. Kirby M., Xanthakos S. A. et al., "High-fructose, medium chain transfat diet induces liver fibrosis and elevates plasma coenzyme Q9 in a novel murine model of obesity and nonalcoholic steatohepatitis," Hepatology,52,3, 934-944, 2010.

44- Ishimoto T., M. A. Lanaspa M.A., C. J. Rivard C.J. et al., "High-fat and high-sucrose (western) diet induces steatohepatitis that is dependent on fructokinase," Hepatology, 58. 5, 1632-1643, 2013.

45-.Masterton G. S, Plevris J. N., and Hayes P. C. "Review article: omega-3 fatty acids - a promising novel therapy for non-alcoholic fatty liver disease," Alimentary Pharmacology and Therapeutics,31,7, 679-692, 2010.

46-Devlin TM : Textbook of Biochemistry: With Clinical Correlations. 18 ed. Hoboken, NJ: John Wiley \& Sons, 2011.

47-Choi SS, and Diehl AM. : Hepatic triglyceride synthesis and nonalcoholic fatty liver disease. 
Current Opinion in Lipidology; 19(3):295-300, 2008.

\section{8-Lefebvre P, Chinetti G, Fruchart JC, Staels}

B. Sorting out the roles of PPAR-alpha in energy metabolism and vascular homeostasis. J Clin Invest. 116(3):571-80, 2006.

49-Mandard S, Muller M, Kersten S. Peroxisome proliferator-activated receptor-alpha target genes. Cell Mol Life Sci.61:393-416, 2004.

50-Panchal S K. Poudyal H, Iyer A, Nazer R, Alam A, Diwan V, Kauter K, Sernia C, Campbell F, Ward L, Gobe G, Fenning A, Brown L. High-carbohydrate high-fat dietinduced metabolic syndrome and cardiovascular remodeling in rats. J Cardiovasc Pharmacol; 57(1):51-64, 2011.

51-Marchesini G, Moscatiello S, Di Domizio S, Forlani G. Review Obesity-associated liver disease. J Clin Endocrinol Metab.; 93(1):S74-80, 2008.

52-Sorbi D, Boynton J, Lindor KD. The ratio of aspartate aminotransferase to alanine aminotransferase: potential value in differentiating nonalcoholic steatohepatitis from alcoholic liver disease. Am J Gastroenterol.; 94(4):1018-22, 1999.

53-B rowning JD, Szczepaniak LS, Dobbins R, Nuremberg P, Horton JD and Cohen JC. Prevalence of hepatic steatosis in an urban population in the United States: impact of ethnicity. Hepatology; 40: 1387-1395, 2004.

54- Calvaruso V, Craxi A. Implication of normal liver enzymes in liver disease. $\mathbf{J}$ Viral Hepat.16:529-36, 2009.
55-Harris on SD Jr, Burdeshaw JA, Crosby RG, Cusic AM, Denine EP. Hematology and clinical chemistry reference values for C57BL/6 X DBA/2 F1 mice. Cancer Res. 38:2636-9, 1978.

56 Sanches, S.C., Ramalho, L.N., Augusto,M.J., da Silva, D.M., Ramalho, F.S. NonalcoholicSteatohepatitis: A Search for Factual Animal Models. Biomed. Res. Int. 2015.

57- Kohli R., Kirby M., Xanthakos S. A. et al., "High-fructose, medium chain trans-fat diet induces liver fibrosis and elevates plasma coenzyme Q9 in a novel murine model of obesity and nonalcoholic steatohepatitis," Hepatology, 5(3)934-944, 2010.

58-Park EJ, Lee JH, Yu GY, et al.: Dietary and genetic obesity promote liver inflammation and tumorigenesis by enhancing IL-6 and TNF $\alpha$ expression. Cell; 140(2):197-208, 2010.

\section{9- Saggese G, Federico G, Balestri M, Toniolo}

A .Calcitriol inhibits the PHA-induced production of IL-2 and IFN-gamma and the proliferation of human peripheral blood leukocytes while enhancing the surface expression of HLA class II molecules. J Endocrinol Invest 12:329-335,1989.

60-Hünkar T, Aktan F, Ceylan A, Karasu Ç . Effects of cod liver oil on tissue antioxidant pathways in normal and streptozotocin- diabetic rats (The ADIC Study Group). Cell Biochem Funct 20:297-302,2002.

61- Aragno M, Tamagno E, Gatto V, B rignardello E, Parola S, Danni O, Boccuzzi G. Dehydroepiandrosterone protects tissues of streptozotocin-treated rats against oxidative stress. Free Radic Biol Med 26:1467-1474,1999. 
62-Toyama TToyama T, Nakamura H, Harano Y, Yamauchi N, Morita A, Kirishima T, Minami M, Itoh Y, Okanoue T. PPAR-alpha ligands activate antioxidant enzymes and suppress hepatic fibrosis in rats. Biochem Biophys Res Commun. 12;324 (2):697-704, 2004.

63-Roth CL, Elfers CT, Figlewicz DP, et al. Vitamin D deficiency in obese rats exacerbates nonalcoholic fatty liver disease and increases hepatic resistin and Toll-like receptor activation. Hepatology.;55: 1103-11., 2012.

\section{4- Sharifi N, Amani R, Hajiani E, Cheraghian}

B. Does vitamin D improve liver enzymes, oxidative stress, and inflammatory biomarkers in adults with nonalcoholic fatty liver disease? A randomized clinical trial. Endocrine 47: 70-80, 2014.

65- Hayden MS, Ghosh S. Signaling to NFkappaB. Genes Dev.18: 2195-2224, 2004.

66-Cohen-Lahav M., Shany S., Tobvin D., Chaimovitz C., Douvdevani A. Vitamin D decreases NF kappa B activity by increasing I kappa B alpha levels. Nephrol. Dial. Transplant. 21:889-897, 2006.

67-Larter CZ, Yeh MM, Van Rooyen DM, Brooling J, Ghatora K, Farrell GC.

Peroxisome proliferator-activated receptor- $\alpha$ agonist, Wy 14,643, improves metabolic indices, steatosis and ballooning in diabetic mice with nonalcoholic steatohepatitis.J Gastroenterol Hepatol.; 27(2):341-50, 2012. 